\title{
The relationship between information technology acceptance and organizational agility in Malaysia.
}

\begin{abstract}
We examined the influence of information technology (IT) acceptance on organizational agility. The study was based on a well-established theoretical model, the Technology Acceptance Model (TAM). We attempted to identify the relationships between IT acceptance and organizational agility in order to see how the acceptance of technology contributes to a firm's ability to be an agile competitor. Structural equation modeling techniques were used to analyze the data. Results from a survey involving 329 managers and executives in manufacturing firms in Malaysia showed that actual system or technology usage had the strongest direct effect on organizational agility. Meanwhile, perceived usefulness and perceived ease of use of IT influenced organizational agility indirectly through actual systems or technology use and attitudes towards using the technology. The results have several implications for IS management.
\end{abstract}

Keyword: IT acceptance; IT adoption; Organizational agility; Structural equation models; Malaysia. 